Visible luminescence of erbium oxide layers grown on crystalline and amorphous silicon

This article has been downloaded from IOPscience. Please scroll down to see the full text article.

2002 J. Phys. D: Appl. Phys. 35295

(http://iopscience.iop.org/0022-3727/35/4/303)

View the table of contents for this issue, or go to the journal homepage for more

Download details:

IP Address: 147.96.14.16

The article was downloaded on 21/02/2013 at 16:20

Please note that terms and conditions apply. 


\title{
Visible luminescence of erbium oxide layers grown on crystalline and amorphous silicon
}

\author{
E Nogales ${ }^{1}$, B Méndez ${ }^{1}, \mathrm{~J} \mathrm{Piqueras}^{1}, \mathrm{R}$ Plugaru$^{2}$, A Coraci $^{2}$ and \\ J A García ${ }^{3}$ \\ ${ }^{1}$ Departamento de Física de Materiales, Facultad de Física, Universidad Complutense, \\ 28040 Madrid, Spain \\ ${ }^{2}$ Institute of Microtechnology, Str. Ecou Iancu Nicolae 32 B, Sector 2, 72996 Bucharest, \\ Romania \\ ${ }^{3}$ Departamento de Física Aplicada II, Facultad de Ciencias, Apdo. 644, 48080 Bilbao, Spain
}

Received 7 September 2001

Published 1 February 2002

Online at stacks.iop.org/JPhysD/35/295

\begin{abstract}
Visible luminescence from erbium oxide layers grown on crystalline and amorphous silicon (c-Si and a-Si) has been investigated. The results show strong red and green cathodoluminescence bands due to intraionic $\mathrm{Er}^{3+}$ radiative transitions at room temperature. The use of $\mathrm{c}-\mathrm{Si}$ or a-Si as substrate led to a red or green dominant emission, respectively, which has been explained in terms of the oxygen content in the substrate. The results obtained from samples grown in different atmospheres also support this assumption.
\end{abstract}

\section{Introduction}

The possibility of achieving silicon-based optoelectronic devices, which is related to efforts to develop efficient light emitting silicon, has attracted much attention in the last decade since it allows the device integration in the available silicon $(\mathrm{Si})$ technology. It is well known that $\mathrm{Si}$ is not a suitable semiconductor for optical purposes due to its indirect gap and low quantum efficiency. To overcome these drawbacks, the incorporation of rare earth elements to a Si matrix, in particular erbium (Er) ions, emerges as one promising method to obtain luminescent material, because of the high $\mathrm{Er}^{3+}$ intraionic $4 \mathrm{f}$ emission $[1,2]$. Many attempts have been made to incorporate Er in different $\mathrm{Si}$ substrates, i.e. crystalline [3-5], amorphous [6-8] and/or porous Si [9]. Due to the low diffusivity of Er in $\mathrm{Si}, \mathrm{Er}$ implantation appears as the most common way to dope Si with Er efficiently [10,11]. However, the luminescence efficiency achieved is still rather low and in general restricted to low temperature. Alternatively, Suezawa et al [12] proposed different doping methods and showed that only annealing n-type Czochralski $\mathrm{Si}$ in $\mathrm{Er}$ vapour at high temperatures $\left(1150^{\circ} \mathrm{C}\right)$ led to a strong infrared photoluminescence (PL) emission related to an erbium oxide $\left(\mathrm{Er}_{2} \mathrm{O}_{3}\right)$ overlayer on $\mathrm{Si}$ [12]. On the other hand, it has been generally accepted that the presence of oxygen in Si substrates enhances the efficiency of Er emission $[10,12]$.

$\mathrm{The} \mathrm{Er}^{3+}$ ion also exhibits efficient visible luminescence generated by infrared excitation through up-conversion processes [13]. Luminescence in the visible range produced by Er doping of different semiconductor materials has been reported, e.g. GaN [14-16] and oxides, e.g. $\mathrm{SiO}_{2}$ [17] and $\mathrm{ZnO}-\mathrm{TeO}_{2}$ [18]. The results obtained until now indicate that the light emission both in the visible and in the infrared range is not much influenced by the host lattice.

In this paper, we report strong visible cathodoluminescence (CL), even at room temperature, after Er deposition on $\mathrm{Si}$ followed by thermal treatment. Crystalline and amorphous $\mathrm{Si}$ (c-Si and a-Si) were used as substrates and the thermal treatments were performed in oxygen or nitrogen atmospheres. The CL spectra exhibit three visible bands in the blue, green and red ranges, whose relative intensities depend on the sample and the annealing temperature. The luminescence of $\mathrm{Er}_{2} \mathrm{O}_{3}$ powder used as reference sample was also investigated.

\section{Experimental set-up}

Samples labelled c-Si/Er/O were obtained by vapour deposition of $\mathrm{Er}$ on a c-Si wafer followed by annealing 
at $950^{\circ} \mathrm{C}$ for $1 \mathrm{~h}$ in oxygen atmosphere. In other set of samples, Er deposition was carried out on a-Si and the annealing at $950^{\circ} \mathrm{C}$ for $1 \mathrm{~h}$ was carried out either in oxygen or nitrogen atmosphere. These samples were labelled a-Si/Er/O and $\mathrm{a}-\mathrm{Si} / \mathrm{Er} / \mathrm{N}$, respectively. a-Si films with a thickness of about $2 \mu \mathrm{m}$ were obtained by low-pressure chemical vapour deposition on $\mathrm{Si}$ at $570^{\circ} \mathrm{C}$ and a pressure of 0.4 torr. $\mathrm{The}^{\mathrm{E}} \mathrm{Or}_{2} \mathrm{O}_{3}$ powder with a purity of $99.9 \%$ was provided by Sigma-Aldrich.

The samples were investigated by the CL mode of operation in a Hitachi S2500 SEM, in the temperature range of $80-300 \mathrm{~K}$. For the detection of visible light a Hamamatsu R-928 photomultiplier was used, while for the near infrared light a cooled ADC Ge detector was employed [19]. The PL measurements were performed with a CD 900-spectrometer system from Edinburgh Instruments. The samples were cooled at $10 \mathrm{~K}$ in a closed-cycle helium cryostat. The excitation sources were a $\mathrm{He}-\mathrm{Cd}$ laser of 325 and $442 \mathrm{~nm}$ with an excitation power of $50 \mathrm{~mW}$, and an Ar-ion laser (lines 514.5, 488 and $457.9 \mathrm{~nm}$ ) with an excitation power of $20 \mathrm{~mW}$. $\mathrm{X}$-ray diffraction measurements were carried out to check Er incorporation into Si. In order to study Er distribution, mapping of this element was carried out by X-ray wavelength dispersive spectrometry (WDS) in a JEOL JXA-8900 M superprobe.

\section{Results and discussion}

Typical secondary electron images of the different samples used in this work are shown in figure 1, corresponding to c-Si/Er/O (figure 1(a)), a-Si/Er/O (figure 1(b)) and a-Si/Er/N (figure 1(c)). The nitrogen treated a-Si presents a more uniform surface than the oxygen treated one. The crystalline substrate led to a film with the presence of cracks related to hillocks (figure 1(a)). X-ray diffraction microanalysis has confirmed the presence of $\mathrm{Er}_{2} \mathrm{O}_{3}$ in all the samples. The CL images of the samples were featureless, showing a very homogeneous emission all over the surface.

The CL spectra at 90 and $300 \mathrm{~K}$ of the c-Si/Er/O sample are shown in figures $2(a)$ and $(b)$, respectively. Three set of peaks are observed: (a) a weak blue band with two peaks at 375 and $410 \mathrm{~nm}$, respectively, (b) a sharp, more intense, green band peaked at about $550 \mathrm{~nm}$ and (c) a red band composed of two peaks at 655 and $675 \mathrm{~nm}$ with moderate intensity. These bands correspond to some of the visible intraionic transitions of $\mathrm{Er}^{3+}$ ion in other matrix materials like $\mathrm{GaN}$ [15] and zinc-telluride glasses [18]. The CL spectrum of $\mathrm{Er}_{2} \mathrm{O}_{3}$ powder obtained under the same experimental conditions is also shown in figure 2. The only difference between the c-Si/Er/O spectrum and that of $\mathrm{Er}_{2} \mathrm{O}_{3}$ appears in the blue region in which a broad emission underlying the 375 and $410 \mathrm{~nm}$ peaks is appreciable in the $\mathrm{c}-\mathrm{Si} / \mathrm{Er} / \mathrm{O}$ sample and not in the oxide powder. The relative intensities of the CL visible bands depend on the temperature, as figure 2 shows. The green band is dominant at $90 \mathrm{~K}$ and decreases as the temperature increases, while the red band shows no changes with temperature and becomes dominant in the CL spectrum at room temperature. These trends are the same for the $\mathrm{Er}_{2} \mathrm{O}_{3}$ powder and for the c-Si/Er/O sample and have been previously observed [18] in PL measurements of Er-doped zinc-telluride glasses. The CL signal in the (a)

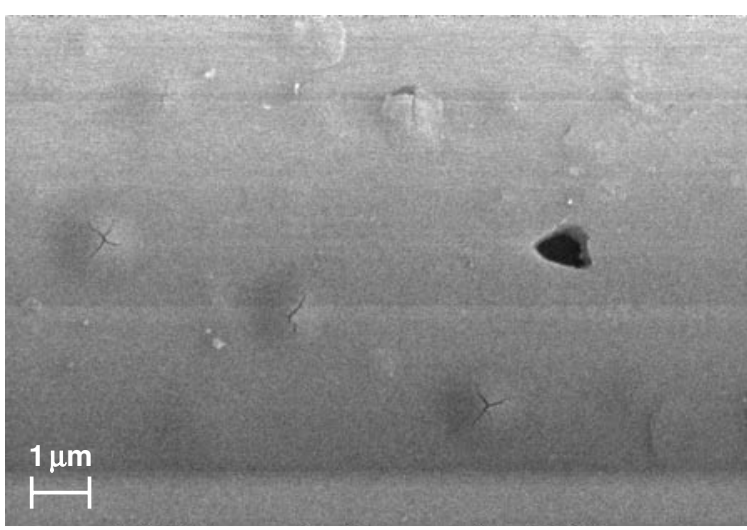

(b)

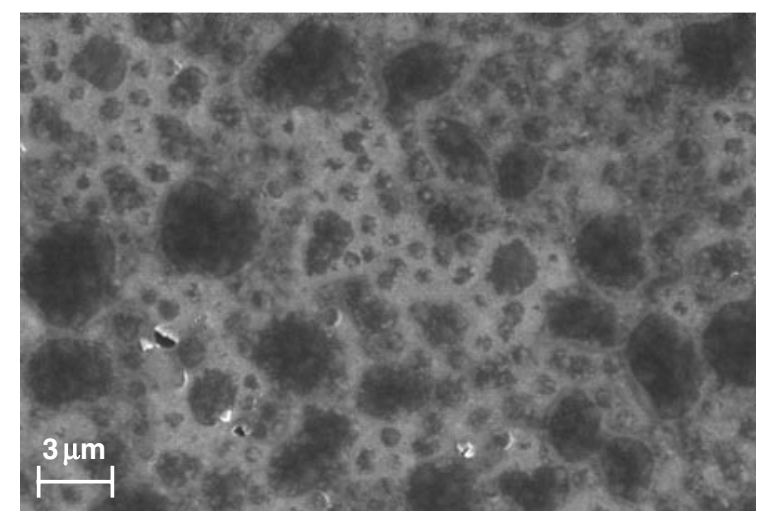

(c)

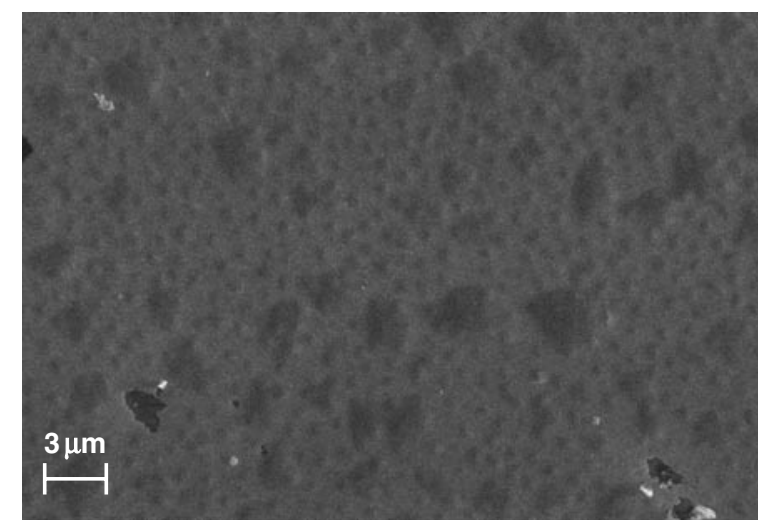

Figure 1. Secondary electron images from $(a) \mathrm{c}-\mathrm{Si} / \mathrm{Er} / \mathrm{O}$, (b) $\mathrm{a}-\mathrm{Si} / \mathrm{Er} / \mathrm{O}$ and $(c) \mathrm{a}-\mathrm{Si} / \mathrm{Er} / \mathrm{N}$.

infrared range was too weak to record spectra of the $\mathrm{Er}$ treated Si samples but the $\mathrm{Er}_{2} \mathrm{O}_{3}$ powder showed strong CL emission in the $1.0-1.6 \mu \mathrm{m}$ range as well as visible emission (figure 3).

In PL spectra (figure 4) neither green nor red emission has been observed even during excitation with different lasers and wavelengths mentioned above. Only a blue broad band, which could be related to the blue background of the CL spectrum, was detected. Differences between PL and CL spectra have been often reported in semiconductor materials. This is attributed to the different excitation energies used in both kinds of experiments and to a more selective character of the PL excitation. These results suggest that the Er-induced luminescence is only slightly influenced by matrix effects and 
Visible luminescence of erbium oxide layers

(a)

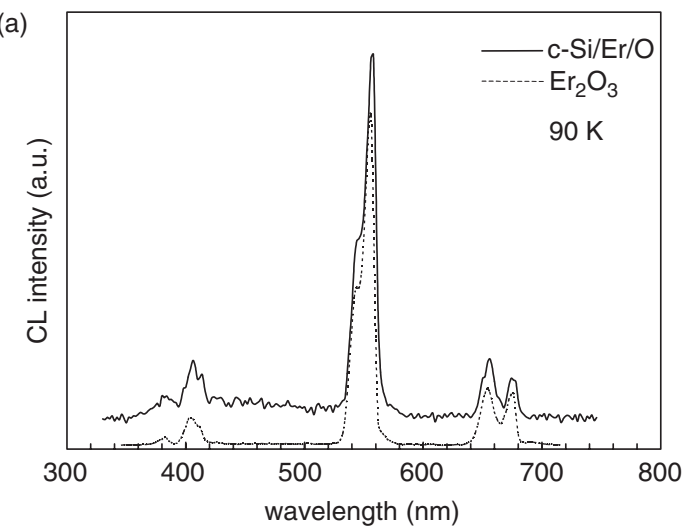

(b)

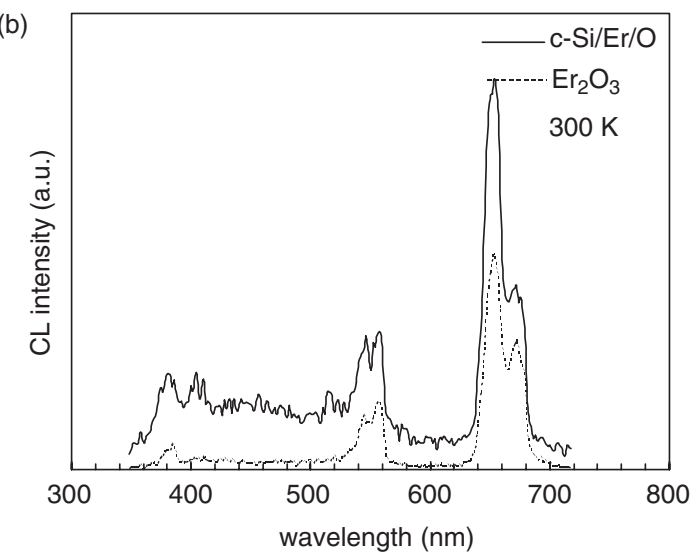

Figure 2. $\mathrm{CL}$ spectra of c-Si/Er/O sample and $\mathrm{Er}_{2} \mathrm{O}_{3}$ powder recorded at $(a) 90 \mathrm{~K}$ and $(b) 300 \mathrm{~K}$.

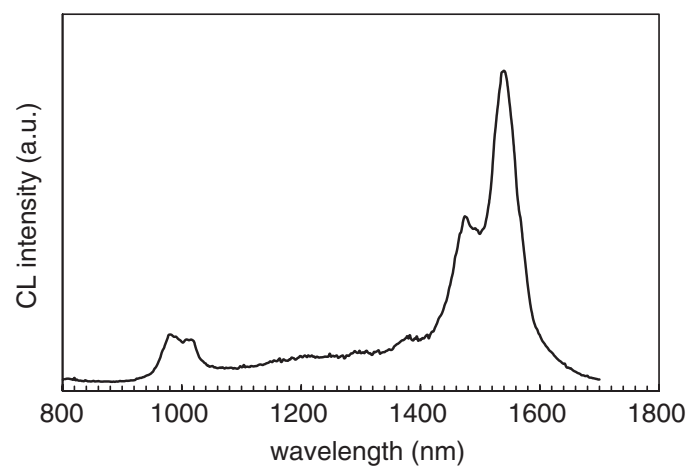

Figure 3. CL spectrum of $\mathrm{Er}_{2} \mathrm{O}_{3}$ powder at room temperature in the infrared range.

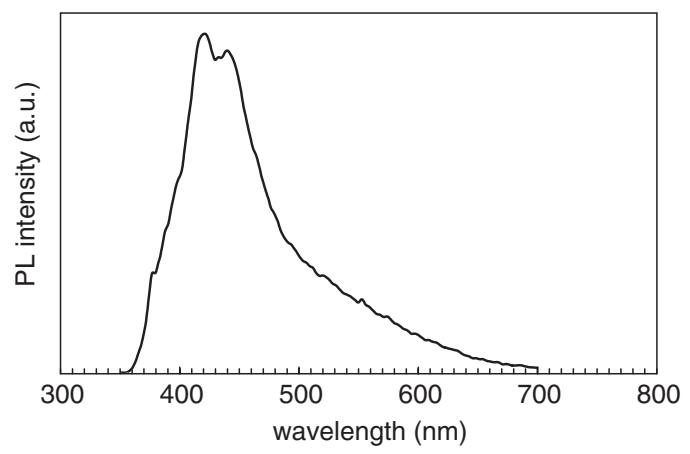

Figure 4. PL spectrum of c-Si/Er/O at $10 \mathrm{~K}$ in the visible range. The excitation wavelength was $325 \mathrm{~nm}$.
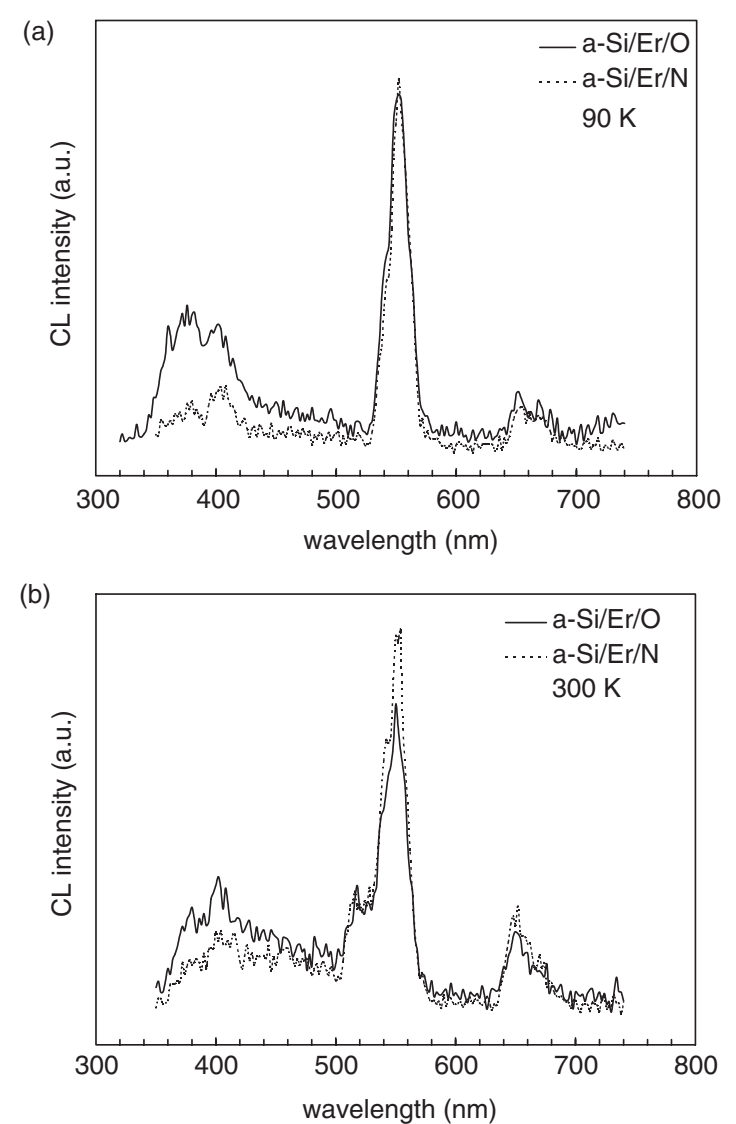

Figure 5. CL spectra of a-Si/Er/O and a-Si/Er/N recorded at (a) $90 \mathrm{~K}$ and (b) $300 \mathrm{~K}$.

confirm that the local environment of the $\mathrm{Er}^{3+}$ ions in Er-doped $\mathrm{Si}$ is similar to the $\mathrm{Er}^{3+}$ environment in $\mathrm{Er}_{2} \mathrm{O}_{3}$, in agreement with previous Mössbauer spectroscopy studies of amorphous hydrogenated $\mathrm{Si}$ [20]. Therefore, the similarities in the visible CL spectra of the c-Si/Er/O and the $\mathrm{Er}_{2} \mathrm{O}_{3}$ samples confirm that the interaction of Er with oxygen plays an important role in the luminescence mechanism. The results also show that the excitation mechanisms and the host matrix have a certain influence on the relative intensities of the CL emission bands.

In the case of Er deposited on a-Si, a strong CL emission in the visible region showing blue, green and red bands (figure 5) is observed in the temperature range of $90-300 \mathrm{~K}$. The green band is always the dominant one in the CL spectra in the whole temperature range. The difference between the CL spectra of $\mathrm{a}-\mathrm{Si} / \mathrm{Er} / \mathrm{O}$ and $\mathrm{a}-\mathrm{Si} / \mathrm{Er} / \mathrm{N}$ samples is apparent in the blue band, which is more intense in the sample treated with oxygen than in the nitrogen treated one. This effect is clearly appreciated in the CL spectra recorded at $90 \mathrm{~K}$ as shown in figure 5(a). A blue emission has been only previously detected in PL studies of up-conversion processes and attributed to intraionic transitions in $\mathrm{Er}^{3+}$ ions [13]. In the PL spectra obtained from c-Si/Er/O samples, the blue band dominates. The present results suggest the possibility of the formation of Er-N complexes besides the Er-O ones which could influence the blue emission. A comparison between the CL spectrum of a c-Si/Er/O sample and a-Si/Er/O one is shown in figure 6 . The 


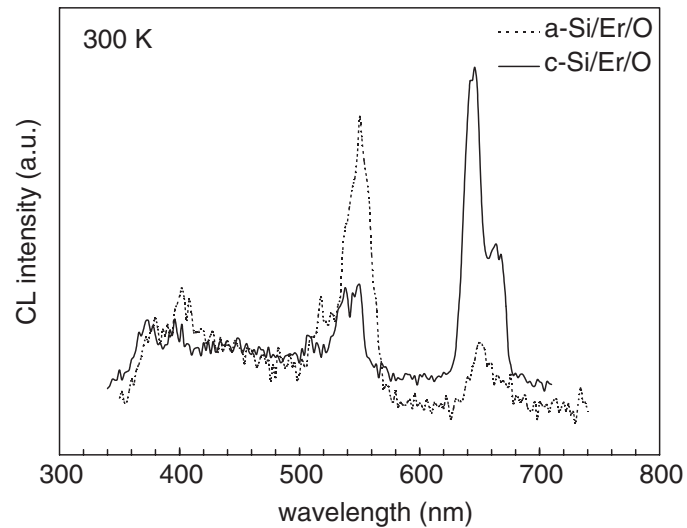

Figure 6. Comparison between the CL spectrum from crystalline and amorphous substrate.

main difference appears in the red band, which is very intense in c-Si but rather weak in a-Si substrate. Jaba [18] reported an increase of the relative intensity of the red band with increasing $\mathrm{Er}_{2} \mathrm{O}_{3}$ concentration. Since the crystalline substrate grown by the Czochralski method has a higher amount of oxygen than the amorphous layer, this result suggests that the formation of $\mathrm{Er}_{2} \mathrm{O}_{3}$ is determined by the oxygen content of the substrate rather than by the atmosphere during the thermal treatment. This possibility is supported by the fact that the red band is similar in $\mathrm{a}-\mathrm{Si} / \mathrm{Er} / \mathrm{O}$ and $\mathrm{a}-\mathrm{Si} / \mathrm{Er} / \mathrm{N}$ samples.

\section{Conclusions}

Electron excitation in the SEM leads to efficient visible CL related to transitions of $\mathrm{Er}^{3+}$ ions in different $\mathrm{Si}$ substrates at room temperature. In fact, narrow green and red dominant $\mathrm{CL}$ emissions were observed in $\mathrm{Er}$ treated a-Si and $\mathrm{c}-\mathrm{Si}$, respectively, possibly due to the different oxygen content in the substrate. Hence, CL is an alternative to the previously reported PL with selective excitation at low temperature to excite luminescence in the visible range. The uses of crystalline or amorphous substrate and of oxygen or nitrogen ambient in thermal treatments induce different competition processes between radiative transitions in $\mathrm{Er}^{3+}$ ions.

\section{Acknowledgments}

This work was supported by DGI (project MAT2000-2119) and by the Scientific Cooperation Program between Spain and Romania.

\section{References}

[1] Coffa S, Polman A and Swartz R N (ed) 1996 Rare earth doped semiconductors II MRS Sym. Proc. No 422

[2] Ennen H, Schneider J , Pomrenke G and Axmann A 1981 Appl. Phys. Lett. $\mathbf{4 3} 943$

[3] Custer J S, Polman A and Van Pinxteren H M 1994 J. Appl. Phys. 752809

[4] Polman A, van den Hoven G N, Custer J S, Serna R and Alkemade P F A 1995 J. Appl. Phys. 771256

[5] Priolo F, Franzò G, Coffa S and A Carnera 1998 Phys Rev. B 574443

[6] van den Hove G N, Shin J H, Polman A, Lombardo S and Campisano S U 1995 J. Appl. Phys. 782642

[7] Zanatta A R, Nunes L A O and Tessler L R 1997 Appl. Phys. Lett. 70511

[8] Fuhs W, Ulber I, Weiser G, Bresler M S, Gusev O B, Kuznetsov A N, Kudoyarova V Kh, Terukov E I and Yassievich I N 1997 Phys. Rev. B 569545

[9] Dorofeev A M, Gaponenko N V, Bondarenko V P, Bachilo E E, Kazuchits N M, Leshok A A, Troyanova G N, Vorosov N N, Borisenko V E, Gnaser H, Bock W, Becker P and Oechsner H 1995 J. Appl. Phys. 772679

[10] Michel J, Benton J L, Ferrante R F, Jacobson D C Eaglesham D J, Fitzgerald E A, Xie Y H, Poate J M and Kimerling L C 1991 J. Appl. Phys. 702672

[11] Polman A 1997 Appl. Phys. Rev: J. Appl. Phys. 821

[12] Suezawa M and Sumino K 1994 Japan. J. Appl. Phys. 33 L1782

[13] Kasuya A and Suezawa M 1997 Appl. Phys. Lett. 712728

[14] Steckl A J, Garter M, Birkhahn R and Scofield J 1998 Appl. Phys. Lett. $\mathbf{7 3} 2450$

[15] Lozykowski H J, Jadwisienczak W M and Brown I 1999 Appl. Phys. Lett. 741129

[16] Heikenfeld J, Lee D S, Garter M, Birkhahn R and Steckl A J 2000 Appl. Phys. Lett. 761365

[17] Polman A, Jacobson D C, Eaglesham D J, Kistler R C and Poate J M 1991 J. Appl. Phys. 703778

[18] Jaba N, Kanoun A, Mejri H, Selmi A, Alaya S and Maaref H 2000 J. Phys.: Condens. Matter 124523

[19] Méndez B and Piqueras J 1991 J. Appl. Phys. 692776

[20] Masterov V F, Nasredinov F S, Seregin P P, Kudoyarova V Kh, Kuznetsov A N and Terukov E I 1998 Appl. Phys. Lett. $\mathbf{7 2} 728$ 